\title{
O USO DOS GRUPOS FOCAIS ON-LINE SÍNCRONOS EM PESQUISA QUALITATIVA ${ }^{1}$
}

\author{
Gabriela Sagebin Bordini* \\ Tania Mara Sperb"
}

\begin{abstract}
RESUMO. No Brasil, ainda hoje são pouco comuns os trabalhos que utilizam o computador e a Internet para coletar dados na pesquisa qualitativa em psicologia. Poucos são os estudos, por exemplo, que trabalham com grupos focais realizados via Internet, ao invés de utilizarem o clássico formato presencial. A técnica dos grupos focais on-line síncronos, contudo, não consiste na mera transposição dos tradicionais grupos focais para o ambiente virtual. Essa nova ferramenta, ao ser introduzida no conjunto dos procedimentos de pesquisa, carrega consigo suas especificidades, modificando o método qualitativo. Cabe, então, divulgar o uso de tal técnica mostrando suas particularidades para, assim, contribuir para o avanço da pesquisa qualitativa em psicologia. Neste trabalho, descreve-se o uso que foi feito dos grupos focais on-line síncronos em uma pesquisa qualitativa, para recuperar as etapas realizadas e relatar as especificidades encontradas.
\end{abstract}

Palavras-chave: Grupos focais on-line; pesquisa qualitativa; Internet.

\section{SYNCHRONOUS ON-LINE FOCUS GROUPS IN QUALITATIVE RESEARCH}

\begin{abstract}
Studies using computers and Internet to collect data are still unusual in the psychological qualitative research in Brazil. There are few researches, for instance, working with focus groups conducted via Internet, instead of using the classic face-to-face model. The technique of synchronous on-line focus groups, however, is not a mere transposition of traditional focus groups to the virtual environment. Introducing this new tool in the set of research procedures modifies the qualitative method because of its special features. It is important, then, to exemplify the use of this technique, highlighting its particularities, and thus to contribute to the progress of the qualitative research in psychology. This article describes the use that was made of synchronous on-line focus groups in a qualitative research, retrieving the steps taken and reporting its specificities.
\end{abstract}

Key words: On-line focus groups; qualitative research; Internet.

\section{LOS GRUPOS FOCALES VIRTUALES SINCRÓNICOS EN PESQUISA CUALITATIVA}

RESUMEN. Aún hoy día, los estudios que utilizan las computadoras y la Internet para recoger datos son poco comunes en la investigación cualitativa en el Brasil. Hay pocas investigaciones, por ejemplo, que trabajan con grupos focales realizados a través de Internet, en lugar de usar el clásico modelo presencial. La técnica de grupos focales virtuales sincrónicos, sin embargo, no es una mera transposición de los grupos focales tradicionales para el entorno virtual. La introducción de esta nueva herramienta en el conjunto de procedimientos de investigación modifica el método cualitativo, por agregar a esto sus especificidades. Vale la pena, pues, ejemplificar el uso de esta técnica, poniendo de relieve sus particularidades y contribuyendo, así, al progreso de la investigación cualitativa en psicología. Este artículo describe la utilización que se hizo de los grupos focales virtuales sincrónicos en un estudio cualitativo, informando las fases de su ejecución y revelando sus especificidades.

Palabras-clave: Grupos focales virtuales; investigación cualitativa; Internet.

No momento em que foi realizada esta investigação, em 2009, os trabalhos que utilizavam o computador e a Internet para a execução de grupos focais praticamente inexistiam na pesquisa qualitativa

\section{Apoio: CNPq e CAPES.}

Mestre em Psicologia pela Universidade Federal do Rio Grande do Sul, Brasil.

If Doutora em Psicologia do Desenvolvimento pela University of London, Grã-Bretanha. Professora colaboradora da Universidade Federal do Rio Grande do Sul, Brasil. 
em psicologia no Brasil. Diante disso, foi necessário basear-se em alguns procedimentos utilizados por outras áreas da ciência, selecionando aquilo que se aplicava aos objetivos da pesquisa em questão. Este trabalho pretende, justamente, recuperar tais passos e relatar as peculiaridades encontradas pelo caminho, com vista a compartilhá-los e, assim, contribuir para o avanço da pesquisa qualitativa em psicologia.

\section{A INVESTIGAÇÃO REALIZADA E A OPÇÃO PELA TÉCNICA DOS GRUPOS FOCAIS ON-LINE SÍNCRONOS}

O objetivo da pesquisa realizada era conhecer as concepções de adolescentes sobre o que é ser homem e o que é ser mulher na atualidade. Tinha-se como base a ideia de que os significados atribuídos ao masculino e ao feminino são culturalmente construídos e transmitidos socialmente por meio da interação (Diamond, 2002; Louro, 2004). Além disso, compartilhava-se do entendimento de Bruner (2000), segundo o qual essa relação com a cultura depende da comunicação entre os indivíduos e torna-se possível a partir da narrativa.

Neste sentido se optou por trabalhar com as narrativas produzidas por adolescentes em interação através de uma investigação qualitativa. A perspectiva qualitativa, conforme explicam Abreu, Baldanza e Gondim (2009), considera que o homem se constitui como pessoa a partir das interações sociais. Tal característica torna-o um objeto de pesquisa diferente dos objetos de pesquisa de natureza física por ele ser capaz de refletir sobre si e sobre o outro. Em face dessa particularidade, uma das técnicas de coleta de dados usadas em pesquisa qualitativa é a entrevista grupal (Abreu et al., 2009).

Nas entrevistas grupais o entrevistador estabelece relações diádicas, ou seja, relaciona-se com cada um dos componentes, o que lhe confere um papel mais diretivo em relação ao grupo (Gondim, 2002). Por esse motivo, tal técnica não pareceu adequada à pesquisa em questão, que tinha como pressuposto a importância conferida à interação. Diante disso, decidiu-se pela utilização de grupos focais. De fato, o uso dessa técnica em estudos de diversas áreas vem crescendo desde os anos 80 , sobretudo em pesquisas qualitativas que procuram coletar dados por meio da interação grupal (De Antoni et al., 2001).

Abreu et al. (2009) salientam que, apesar de apoiados no desenvolvimento de entrevistas grupais, os grupos focais diferenciam-se dessas pela preocupação do moderador com as relações entre os membros e com o processo de discussão, que geram respostas às questões da pesquisa. Essa modalidade qualitativa toma o grupo como uma unidade e pode ser utilizada para reunir informações, explorar temas pouco conhecidos e até para promover autorreflexão e transformação social (Gondim, 2002).

Mais recentemente, a coleta de dados com a utilização de grupos focais foi potencializada pela difusão das novas tecnologias de comunicação, as quais permitiram que fosse realizada em ambientes virtuais (Abreu et al., 2009). A Internet, de fato, vem se constituindo como um dos contextos de interação privilegiados pelos adolescentes (Subrahmanyam, Smahel \& Greenfield, 2006). Como, no Brasil, os grupos etários mais jovens são os que mais acessam a rede (IBGE, 2008), pensou-se, nesta pesquisa, em realizar os grupos focais virtualmente. O problema enfrentado foi a inexistência de trabalhos científicos brasileiros com esse formato na área da psicologia.

\section{A TÉCNICA DOS GRUPOS FOCAIS ON-LINE SÍNCRONOS}

Nos últimos anos, referências ao uso da técnica dos grupos focais on-line vêm se tornando cada vez mais presentes na literatura científica (Fox, Morris \& Rumsey, 2007). Nos grupos focais on-line síncronos os participantes interagem em tempo real, ou seja, simultaneamente (Walston \& Lissitz, 2000), reunidos em salas de bate-papo (chat) ou por meio de programas de computador que possibilitam conferências on-line, como o MSN ou o MIRC (Duarte, 2007).

Estando todos on-line, o moderador inicia a discussão apresentando-se aos participantes. Ato contínuo ele assegura a confidencialidade dos dados ali gerados (Walston \& Lissitz, 2000) e faz uma introdução sobre o que será realizado (Duarte, 2007). Em seguida envia a questão de abertura da pesquisa. Os comentários e a identificação do participante que os fez vão aparecendo na tela de cada membro, de acordo com a ordem em que foram postados. Na parte de baixo da tela há uma caixa de texto para que o usuário escreva o seu comentário (Bordini, 2010).

Embora os grupos virtuais apresentem algumas semelhanças com os grupos presenciais - quanto ao conteúdo das opiniões obtidas (Duarte, 2007; Walston $\&$ Lissitz, 2000) e quanto ao formato do grupo (Chase \& Alvarez, 2000), por exemplo - os grupos virtuais contam com algumas particularidades. A técnica dos grupos focais on-line, então, não consiste na mera transposição dos tradicionais grupos focais para o ambiente virtual. Conforme explicam Nicolaci-daCosta, Romão-Dias e Di Luccio (2009), quando se 
introduz uma nova ferramenta de coleta de dados em um conjunto de procedimentos preexistente, todo o sistema que caracteriza tal método se modifica. Cabe, então, exemplificar o uso desse novo instrumento, descrevendo suas particularidades.

\section{QUANDO UTILIZAR OS GRUPOS FOCAIS ON- LINE?}

De acordo com a literatura especializada, uma das maiores vantagens dessa técnica é a possibilidade de utilizá-la nos casos em que é necessário eliminar custos com o deslocamento dos participantes (Walston \& Lissitz, 2000). Os grupos focais on-line síncronos são úteis também em pesquisas que pretendam obter dados de uma população espalhada por locais distantes (Schneider, Kerwin, Frechtling \& Vivari, 2002), isto é, pessoas de difícil acesso. Por outro lado, o uso da comunicação mediada por computador é desaconselhado na pesquisa com participantes não acostumados com o meio virtual ou com o uso do computador (Chase \& Alvarez, 2000; Walston \& Lissitz, 2000), e com pessoas muito jovens, com alfabetização deficiente ou com pouca habilidade de digitação (Walston \& Lissitz, 2000).

Ressalta-se que a utilidade dos grupos focais online como técnica de coleta de dados depende do propósito da discussão a ser realizada (Fox et al., 2007). Chase e Alvarez (2000) consideram que os grupos focais on-line podem ser usados para explorar ideias e abordar percepções e sentimentos, sobretudo quando estão em pauta tópicos delicados, com os quais pode ser difícil lidar presencialmente. A opção pela técnica on-line é aconselhada, principalmente, nos casos em que a Internet é o setting natural dos participantes (Alvarez, Cuenca, Noronha \& Schor, 2007), um ambiente com o qual eles estejam totalmente familiarizados.

Neste sentido, a população jovem vem sendo associada aos grupos focais on-line, pois muitos jovens, adultos e adolescentes estão acostumados com conversas eletrônicas (Alvarez et al., 2007; Chase \& Alvarez, 2000; Duarte, 2007) e interagem com naturalidade através dessa nova tecnologia de comunicação (Fox et al., 2007). Este público troca opiniões facilmente neste meio, graças à sensação de anonimato que a Internet oferece (Chase \& Alvarez, 2000).

De acordo com esses dados, os grupos focais online síncronos parecem ser um instrumento que fomenta a interação, possibilitando que adolescentes produzam narrativas. Diante disso, surpreende o fato de que a pesquisa qualitativa em psicologia não se utilize com frequência dos grupos focais on-line. Como essa técnica ainda está em construção e a reflexão sobre os métodos envolvidos nas pesquisas mediadas pela Internet está apenas começando (Whitehead, 2007), acredita-se que seja útil relatar uma experiência com grupos focais on-line síncronos.

Este trabalho objetiva, justamente, descrever o uso que foi feito dos grupos focais on-line síncronos em uma pesquisa qualitativa, bem como examinar as particularidades encontradas. Essa técnica foi utilizada em um estudo com adolescentes para coletar narrativas interacionais e, assim, acessar as concepções dos participantes sobre o que é ser homem e ser mulher atualmente.

\section{DESCRIÇÃO DA INVESTIGAÇÃO REALIZADA}

Procurou-se um método de investigação e um instrumento de coleta de dados que fossem adequados ao referencial teórico e ao objetivo proposto, seguindo o procedimento - habitual em pesquisas qualitativas de escolher os métodos que pareçam mais sensíveis aos objetivos do estudo (Nicolaci-da-Costa et al., 2009). Assim, realizou-se uma pesquisa exploratória com a utilização de grupos focais on-line síncronos para coletar narrativas interacionais que revelassem as concepções dos adolescentes sobre o que é ser homem e o que é ser mulher.

\section{ETAPAS DA REALIZAÇÃO DO GRUPO FOCAL ON-LINE SÍNCRONO}

A realização do grupo focal on-line compreende seis etapas, as quais são expostas e descritas a seguir.

\section{Seleção da amostra}

\section{Recrutamento dos participantes}

Seguindo o padrão dos estudos qualitativos presenciais, o recrutamento dos participantes tende a ser intencional, ou seja, por conveniência (Maxwell, 2005). Assim como nos grupos focais presenciais, nos grupos focais on-line síncronos a seleção pode visar reunir pessoas que tenham em comum algum aspecto determinado ou pessoas que, estando de acordo com um dado padrão, difiram em algum ponto específico. Um detalhe que não se pode esquecer é que haverá, de antemão, um critério comum a todos os participantes de um grupo focal on-line: ser capacitado para o uso das ferramentas de comunicação virtual.

O recrutamento pode ser realizado presencialmente, como ocorreria na execução de 
grupos focais tradicionais; mas é possível fazê-lo online, de diferentes maneiras. Segundo Whitehead (2007), um modo seria anunciar a pesquisa em um determinado site; outra forma seria convidar membros de grupos ou fóruns virtuais específicos. O convite feito a partir do envio de um e-mail não solicitado costuma gerar uma taxa de participação mais baixa do que aquele executado segundo os métodos mais tradicionais, e deve ser feito individualmente, para preservar o anonimato dos participantes.

Quanto à veracidade dos dados biossociodemográficos dos recrutados, a literatura é controversa. Segundo Huffaker e Calvert (2005), o anonimato decorrente do uso da Internet não implica em fingimentos por parte dos seus usuários. Esses autores encontraram que os participantes da sua pesquisa frequentemente revelavam informações pessoais - nome completo, idade e lugar onde moravam. Não obstante, deve-se esclarecer que seu estudo trabalhou apenas com jovens. Pesquisa realizada no Brasil, também com o público jovem, obteve resultados diferentes, levando os autores a não considerarem a Internet como um espaço especial para a revelação de aspectos pessoais. No estudo de Dias e La Taille (2006), homens e mulheres jovens referiram modificar informações como idade, nome e aparência física, tanto por segurança e discrição quanto por diversão.

Diante desses dados, na presente pesquisa optouse por realizar o recrutamento presencialmente. A escolha por fazê-lo com o auxílio das escolas baseouse na pressuposição de que nesse espaço seria fácil encontrar adolescentes que estivessem habituados a usar a Internet como meio de comunicação. Além disso, foi bastante simples entregar pessoalmente aos participantes os termos de consentimento livre e esclarecido e a ficha de dados sociodemográficos, bem como confirmar com a escola alguns desses dados.

\section{Número de participantes}

Há consenso quanto à adequação do uso de um pequeno número de participantes em pesquisas qualitativas (Nicolaci-da-Costa et al., 2009). Especificamente em relação aos grupos focais, tem-se que, em geral, participam de seis a doze pessoas (Duarte, 2007). Na opinião de Schneider et al. (2002), nos grupos focais on-line pode haver um número maior de componentes, dada a impossibilidade de um membro interromper a participação do outro. No entanto os pesquisadores que vêm se utilizando dessa técnica costumam manter o número de participantes dos grupos focais presenciais (Alvarez et al., 2007;
Chase \& Alvarez, 2000; Duarte, 2007; Walston \& Lissitz, 2000), ou mesmo omitir essa informação.

Nesta pesquisa foi necessário trabalhar com o número mínimo indicado, pois o estudo piloto mostrou que a quantidade de dez participantes por grupo focal on-line síncrono era excessiva. Optou-se por formar grupos de sete componentes, já que sua execução com dez membros dificultou o diálogo entre eles e tornou o grupo difícil de moderar.

\section{Escolha do programa de comunicação a ser utilizado}

Nos programas de conferências on-line - como o MSN, por exemplo - os comentários e a identificação do participante que os postou vão aparecendo na tela de cada componente do grupo, na ordem em que foram enviados (Bordini, 2010). Para ler as mensagens postadas anteriormente, basta clicar no comando específico para isso (Walston \& Lissitz, 2000). Para escrever os seus comentários, os membros do grupo devem escrever sua mensagem em uma caixa de texto posicionada, geralmente, na parte de baixo da tela. Chase e Alvarez (2000) recomendam atenção na escolha do programa, pois alguns impõem um limite de linhas a serem escritas.

No estudo realizado utilizou-se o programa de computador Windows Live Messenger (MSN) da Microsoft, na sua versão 8.1, e se trabalhou com a troca de mensagens por escrito. Essas opções basearam-se na difusão desse programa entre os jovens brasileiros para a comunicação virtual por escrito.

\section{Procedimentos prévios à realização do grupo focal on- line síncrono}

\section{Construção do guia de entrevista}

Assim como os grupos focais presenciais, os grupos focais on-line síncronos também costumam contar com um roteiro de questões elaborado previamente. Esse guia não costuma apresentar diferença em relação àquele utilizado nos grupos focais presenciais (Chase \& Alvarez, 2000; Duarte, 2007). Trata-se de um roteiro de entrevista elaborado pelo pesquisador e utilizado pelo moderador para reorientar a discussão, caso os participantes se dispersem ou se desviem do tema proposto (Duarte, 2007). Krueger e Casey (2000) sugerem que as questões do guia sejam subdivididas em categorias, como, por exemplo, objetivo, forma de utilização e momento de aplicação; contudo, ainda que seja importante a elaboração desse roteiro para auxiliar no trabalho do moderador, os direcionamentos realizados 
devem ser sutis, pois a dinâmica do grupo focal não pode parecer rígida ou inflexível (Duarte, 2007).

Como sugerem Nicolaci-da-Costa et al. (2009) em relação ao roteiro para entrevistas on-line, é prudente elaborar um primeiro rascunho de guia para grupo focal on-line síncrono e testá-lo em estudos piloto. No caso da pesquisa realizada, não houve necessidade de preparar um roteiro de questões, pois o objetivo era coletar histórias produzidas em meio à interação do grupo, e não fomentar uma discussão propriamente dita.

\section{Escolha do local de realização do grupo focal on-line}

Após a manifestação de interesse por parte das pessoas convidadas, envia-se um $e$-mail explicando os objetivos da pesquisa e os procedimentos para a participação (Chase \& Alvarez, 2000; Duarte, 2007). Não obstante, embora geralmente, nos grupos focais on-line, cada participante se encontre em um lugar diferente, existe a possibilidade de realizar grupos síncronos nos quais os membros estejam na mesma sala, com os computadores ligados em rede (Walston \& Lissitz, 2000).

A ideia original para o estudo em questão envolvia a realização dos grupos focais on-line sem nenhum encontro presencial entre os participantes. Seria marcado um horário para que todos acessassem o MSN simultaneamente, cada um do seu computador pessoal, não importando a localização deste; mas surgiram algumas dificuldades em relação a esse formato, sobretudo quanto ao comprometimento dos adolescentes em se conectar em um determinado horário e no sentido de pedir aos seus responsáveis que estimulassem o filho a utilizar a Internet sem um controle externo. Diante disso, preferiu-se realizar o estudo no contexto escolar, na sala de informática da escola em que estudavam os adolescentes.

\section{Consentimento livre e esclarecido}

Nos grupos focais on-line, o termo por meio do qual o indivíduo consente em participar da pesquisa é enviado via e-mail (Kralik, Price, Warren \& Koch, 2006). Cameron et al. (2005) fizeram contato com os responsáveis pelos participantes tanto por e-mail quanto por telefone, na tentativa de obter uma autorização verbal e escrita. Whitehead (2007), por sua vez, propõe que se coloque no ar um site do estudo no qual haja um espaço em que o participante possa clicar para indicar que leu as informações sobre a pesquisa e que concordou em participar; porém o próprio autor ressalta que, se o termo de consentimento livre e esclarecido não for entregue em mãos e assinado na presença do pesquisador, não será possível ter certeza da veracidade da assinatura e da anuência do participante (Whitehead, 2007).

Diante disso e do fato de que, na pesquisa realizada, o contato prévio com os participantes foi integralmente presencial, optou-se por entregar os termos e recebê-los pessoalmente. Todos os adolescentes que se dispuseram a colaborar, bem como os seus responsáveis, assinaram um termo de consentimento livre e esclarecido e o entregaram em mãos.

\section{Confidencialidade das informações fornecidas}

Kralik et al. (2006) e Whitehead (2007) apontam que a confidencialidade dos dados obtidos a partir de grupos virtuais dificilmente pode ser garantida. Em grupos focais on-line síncronos, as mensagens na tela do computador podem ser lidas por qualquer pessoa que passe pelo local em que o participante se encontra. Além disso, os endereços de e-mail dos componentes ficam disponíveis aos outros membros durante toda a duração do grupo focal. Por essa razão, no presente estudo o pesquisador forneceu aos participantes os endereços de $e$-mail que seriam utilizados na pesquisa enviando-os a eles individualmente por correio eletrônico. Isso evitou que os membros do grupo tivessem acesso aos $e$-mails pessoais uns dos outros, o que dificultou também a identificação de uns componentes pelos outros.

Também é fundamental que o pesquisador escolha um programa de computador que restrinja a participação no grupo apenas àqueles que foram convidados e se dispuseram a participar. Kelly e McKenzie (2002) acrescentam que o antivírus dos computadores deve estar atualizado, para evitar que o computador dos participantes seja infectado e que os dados revelados sejam acessados por outrem. Para lidar com essas especificidades dos grupos focais on-line, Kralik et al. (2006) sugerem que a equipe de pesquisa inclua um expert em tecnologias da informação.

Por último, ressalta-se que Walston e Lissitz (2000) encontraram sinais de que o modelo de grupo focal presencial ou on-line - não afeta a percepção dos participantes quanto à confidencialidade dos dados. Ainda assim, aconselha-se que o moderador do grupo estabeleça regras de confidencialidade com os participantes antes do início da discussão on-line, ressaltando a importância de que as informações ali fornecidas não sejam relatadas a terceiros (Kralik et al., 2006).

\section{Execução do grupo focal on-line síncrono}

Resumidamente, na execução de um grupo focal on-line síncrono o moderador segue um guia de 
entrevista previamente elaborado e os participantes discutem o tópico proposto como nos grupos focais presenciais. Contudo, nos grupos on-line, os comentários são feitos por escrito e lidos na tela do computador. No caso desta pesquisa, pretendeu-se discutir os significados atuais de ser homem e de ser mulher.

Quando todos os participantes já tiverem sido informados sobre os procedimentos do grupo focal síncrono - como acessar o programa, data e hora de participação - basta aguardar o momento combinado para iniciar a reunião on-line. É importante lembrar aos participantes que devem criar um pseudônimo ou nick ao qual apenas o moderador terá acesso (Walston \& Lissitz, 2000). Isso feito, o moderador relembra o objetivo da pesquisa e ressalta que os dados obtidos serão mantidos em sigilo. Após uma rápida conversação para testar se todos conseguem enviar e receber mensagens, pode-se dar início à discussão e lançar a questão de abertura.

Evidentemente, todos esses passos são realizados virtualmente nos grupos focais on-line síncronos, conforme se encontra na literatura especializada (Duarte, 2007; Walston \& Lissitz, 2000); mas nesta pesquisa havia a possibilidade de se comunicar com os participantes presencialmente, antes do início da discussão virtual propriamente dita, pois todos se encontravam na mesma sala. Ao chegarem à sala, os adolescentes eram recebidos com os computadores já conectados ao MSN, com endereços de contato criados previamente pela pesquisadora. Cada componente - assim como a moderadora - dispunha de um computador.

$\mathrm{O}$ estudo piloto revelou dificuldade dos componentes em se engajar rapidamente no objetivo do grupo focal e em não interagir oralmente. Diante disso, decidiu-se criar um roteiro de atividades a serem executadas antes do início da comunicação on-line. Em primeiro lugar, era feita a escolha dos nicks. Embora os participantes conseguissem facilmente identificar uns aos outros - por já se conhecerem previamente e estarem uns na presença dos outros anunciava-se que os nicks deveriam assegurar o anonimato dos componentes, pois aqueles dados seriam utilizados para fins da pesquisa.

Depois disso, a pesquisadora lembrava que o objetivo da pesquisa era "conhecer as ideias dos jovens sobre o que é ser homem e o que é ser mulher atualmente" e reforçava a confidencialidade das informações. Por fim, a moderadora alertava que, a partir do momento em que fosse iniciada a comunicação pelo MSN não seria mais permitido interagir oralmente.
Outras combinações podem ser feitas com os participantes a fim de facilitar a comunicação virtual durante o grupo focal on-line síncrono e a posterior análise dos dados obtidos. No presente estudo, por exemplo, os participantes - já conectados - foram orientados a escolher uma cor e um tipo de fonte com os quais deveriam escrever suas mensagens do início ao fim da coleta de dados. Verificando que todos estavam preparados para o início da discussão, a moderadora lançava, então, a seguinte questão de abertura: "Queria que vocês contassem histórias ou situações que mostram bem o que é ser homem ou o que é ser mulher hoje". A partir daí começava a interação voltada para o foco da pesquisa.

A interação, no caso dos grupos on-line, apresenta especificidades. Como descrevem Nicolaci-da-Costa et al. (2009) em relação às entrevistas virtuais, também nos grupos focais on-line fazem-se presentes as rupturas típicas das conversas on-line, isto é, a discussão de um tema é entrecortada por outra discussão ou até mesmo por outros assuntos, podendo ser retomada mais adiante com naturalidade.

Segundo Schneider et al. (2002), os componentes de grupos focais on-line síncronos, em comparação com aqueles dos grupos presenciais, fazem comentários mais curtos e emitem pequenas frases que simplesmente expressam concordância com opiniões já apresentadas. Isso ofereceria uma oportunidade de participação mais equânime, mas também tornaria os comentários produzidos menos elaborados. Os autores explicam que isso pode decorrer da alta velocidade em que se dá a postagem dos comentários, permitindo que a discussão não pare enquanto um participante está escrevendo sua mensagem. De fato, no estudo realizado, a continuidade das narrativas produzidas parece ter sido influenciada pela utilização da técnica dos grupos focais on-line. A rapidez da comunicação virtual, nesse caso, pode ter dificultado a concentração do grupo em um único assunto.

Além disso, na comunicação on-line síncrona não existe a possibilidade de um participante interromper o outro, pois os comentários vão aparecendo na tela de acordo com a ordem em que foram enviados, não sendo necessário esperar que um membro termine de emitir sua opinião para que outro tenha a sua vez. Ocorre, também, um intervalo entre o envio de uma mensagem (que só é realizado quando o participante terminou de escrevê-la e optou por postá-la) e o recebimento da resposta correspondente (Nicolaci-daCosta et al., 2009).

Essas peculiaridades da comunicação on-line fazem com que a interação dos participantes em um grupo focal on-line síncrono dependa da velocidade 
em que cada componente é capaz de escrever suas mensagens e acompanhar as dos outros. Isso torna difícil a manutenção de uma sequência de interações por parte do grupo, pois a comunicação não ocorre de maneira linear. De fato, na pesquisa realizada, a independência entre as participações dos componentes não foi vantajosa à elaboração de narrativas longas ou detalhadas. Ocorreu com frequência, por exemplo, que, enquanto um participante escrevia uma mensagem mais longa ou em resposta a alguma mensagem postada anteriormente, outros já escreviam mensagens relacionadas a outros assuntos.

Diante de tais especificidades, o papel do moderador de um grupo focal on-line síncrono também apresenta aspectos particulares. Tal como nos grupos focais presenciais, os grupos focais online contam com essa figura para facilitar o debate e manter o foco dos participantes no tópico sempre do modo mais natural possível. Nos grupos focais on-line síncronos realizados, por exemplo, a moderadora teve de ser muito rápida na digitação e estar muito atenta à simultaneidade de participações, além de pedir repetidas vezes aos adolescentes que elaborassem melhor as suas colocações. Esses aspectos não estiveram presentes somente nesse estudo, mas foram observados também por outros pesquisadores (Duarte, 2007; Schneider et al., 2002).

Outra característica dos grupos focais on-line síncronos que influencia o trabalho do moderador é a falta de acesso à comunicação não verbal, que auxilia na orientação da discussão nos grupos presenciais (Duarte, 2007; Walston \& Lissitz, 2000). Neste caso, a interpretação dos silêncios, a inferência dos sentimentos dos participantes e a interpretação dos resultados tornam-se mais difíceis (Duarte, 2007; O’Connor \& Madge, 2003). Diante disso, mesmo os moderadores com experiência nos grupos focais presenciais precisam dominar a tecnologia e a linguagem virtual (Chase \& Alvarez, 2000; Duarte, 2007; Walston \& Lissitz, 2000).

Para lidar com essa impossibilidade de interação face a face, existem os "emoticons" (emotion icons). Esses ícones, que têm a forma de um rosto ou de um gesto, são disponibilizados por sites e utilizados com frequência nas conversas mediadas por computador. Os emoticons são enviados junto com as mensagens escritas, para representar expressões faciais e emoções (Alvarez et al., 2007; Chase \& Alvarez, 2000; Duarte, 2007; Kralik et al., 2006). Além dessa ferramenta,
Walston e Lissitz (2000) apontam outras estratégias comuns para enfatizar algo escrito, como as repetições - de pontuação ("???” e "!!!!") e de letras ("siiim") - e o uso de caixa alta ("NÃO"). Todos esses artifícios devem ser conhecidos pelo moderador e pelo responsável pela interpretação dos dados.

Quanto ao encerramento da discussão, salientase que o moderador precisa ter sensibilidade para identificar o cansaço dos participantes e o momento adequado de anunciar que o encontro está chegando ao fim. Kralik et al. (2006) lembram que, nos grupos em que a interação tiver sido profunda e promotora de auxílio, o término da discussão deve ser planejado pelos pesquisadores.

No grupo focal realizado, foi eficaz que a moderadora tenha, esporadicamente, apontado ao grupo em que ponto estava o trabalho, já que a comunicação digitada e fragmentada pode alongar a discussão (Nicolaci-da-Costa et al., 2009). Também a impossibilidade de interrupções pode fazer com que grupos on-line síncronos durem mais tempo do que os grupos presenciais (Schneider et al., 2002). Não obstante, os grupos da pesquisa executada acabaram em aproximadamente uma hora, conforme o relatado por Duarte (2007).

\section{Transcrição dos dados}

Realizado o grupo focal on-line síncrono, a sua transcrição encontra-se automaticamente pronta (Duarte, 2007). No caso deste estudo, toda a conversa por escrito foi automaticamente gravada pelo próprio MSN, gerando um arquivo de texto. Como salientam Nicolaci-da-Costa et al. (2009), a transcrição feita pelo próprio programa é a mais fiel possível, por não estar sujeita a edição ou más interpretações.

Por outro lado, a transcrição de um grupo focal on-line síncrono é mais difícil de ser lida e entendida do que aquela de um grupo focal presencial. A escrita gramaticalmente incorreta torna mais demorada a leitura do texto obtido. Outro complicador pode ser o nick (pseudônimo) dos participantes, que aparece acima de cada mensagem postada por cada componente. Esses nicks são usados como meio de construção e expressão das identidades virtuais dos participantes (Subrahmanyam et al., 2006). Neste caso, podem ser muito longos ou chamativos, o que desvia a atenção do leitor da transcrição.

Além disso, a transcrição mostra fielmente o que ocorre na comunicação on-line simultânea, isto é, a impossibilidade de um participante ser interrompido por outro. Assim, a ordem dos comentários feitos fica 
desorganizada, pois não é necessário que um membro termine de emitir sua opinião para que outro tenha a sua vez. Dessa forma, as participações ficam entrecortadas por comentários referentes a outros tópicos. $\mathrm{O}$ entendimento da sequência da interação fica, então, prejudicado, pois a própria participação dos membros do grupo não é linear.

\section{Análise dos dados}

Conforme descreve Duarte (2007), os procedimentos de análise dos dados obtidos por meio dos grupos focais on-line são os mesmos dos grupos presenciais. A análise de conteúdo pode ser realizada como de hábito e atualmente existem alguns programas de computador que a executam.

$\mathrm{Na}$ pesquisa em questão, as narrativas interacionais produzidas pelos grupos foram submetidas, em primeiro lugar, a uma análise de conteúdo, na qual a unidade de análise foi a narrativa e o foco da análise foram os temas nela presentes. Em um segundo momento foi examinado o conjunto das interações em cada grupo focal on-line. De cada um dos grupos retirou-se um trecho considerado ilustrativo do processo de construção das identidades de gênero dos adolescentes participantes. Os trechos selecionados foram, então, analisados em profundidade, utilizando-se microanálises.

Lembra-se que a realização on-line dos grupos focais influencia a produção dos componentes. Em comparação com os grupos presenciais, nos grupos on-line síncronos os participantes fazem comentários mais curtos e menos elaborados e emitem frases menores (Schneider et al., 2002). Assim, um pesquisador que almeje encontrar narrativas em um formato tradicional terá dificuldades. Neste estudo, por exemplo, todos os grupos apresentaram narrativas fragmentadas, geralmente curtas e entrecortadas por outros assuntos. Essas narrativas seriam classificadas como "pequenas histórias" (Georgakopoulous, 2008), por não corresponderem às narrativas tipicamente obtidas em pesquisas, tratando-se, algumas vezes, de contações de eventos futuros, hipotéticos ou compartilhados (Georgakopoulou, 2007).

\section{CONCLUSÃO}

Conforme salientam Nicolaci-da-Costa et al. (2009), é importante que os pesquisadores aprendam a utilizar os novos contextos comunicativos que despontam atualmente. Visto que tais ambientes vêm se tornando uma alternativa usual de interação, sua utilização pode ser interessante e até mesmo necessária para fins de pesquisa. Por outro lado, não se pode ignorar que o emprego de uma técnica de investigação em um contexto diferente produz alterações na própria técnica.

De fato, a pesquisa realizada mostrou que, em comparação com os grupos focais tradicionais, os grupos focais on-line síncronos apresentam especificidades. As mais marcantes são aquelas relativas à comunicação. Como foi descrito, as discussões nos grupos focais on-line tendem a ser menos contínuas, mais fragmentadas e entrecortadas por assuntos diversos do tópico proposto. Geralmente as participações são curtas e os comentários não são muito elaborados e são emitidos rapidamente, o que significa que o grupo focal on-line síncrono não é uma mera transposição do grupo focal presencial para o ambiente virtual.

Ficou claro que a vantagem da realização on-line de um grupo focal está diretamente relacionada à familiaridade dos participantes com o ambiente virtual. Aconselha-se o seu uso somente quando os membros do grupo têm intimidade com o programa de comunicação a ser utilizado. Neste sentido, pessoas já habituadas às ferramentas comunicacionais oferecidas pela Internet são as mais indicadas a participar dos grupos focais on-line. O domínio do programa de computador também é fundamental ao moderador do grupo, que precisa não apenas estar apto a comunicarse por meio dele, mas também estar plenamente familiarizado com ele, para conseguir moderar adequadamente a discussão.

Um grupo focal on-line síncrono composto por participantes ambientados ao programa de computador utilizado e por um moderador que domine esta técnica pode revelar-se um instrumento interessante para se trabalhar com questões complexas, ao contrário do assinalado por Kralik et al. (2006). Esses autores sugerem que tal ferramenta seria mais adequada para acessar impressões e opiniões relativamente simples e genéricas. Entretanto, no estudo aqui relatado a utilização de grupos focais on-line síncronos contribuiu para a exploração de ideias, percepções e sentimentos, inclusive com referência a tópicos delicados e polêmicos, como Chase e Alvarez (2000) já haviam apontado.

Entende-se, então, que o grupo focal on-line síncrono é uma técnica adequada e conveniente para a pesquisa com populações que têm a Internet como um espaço de expressão e comunicação. A realização do grupo focal em um setting no qual os participantes estão habituados a interagir só tem a acrescentar para a pesquisa em psicologia no Brasil. 


\section{REFERÊNCIAS}

Abreu, N. R., Baldanza, R. F., \& Gondim, S. M. G. (2009). Os grupos focais on-line: das reflexões conceituais à aplicação em ambiente virtual. Revista de Gestão da Tecnologia e Sistemas de Informação, 6, 23-42.

Alvarez, M. C. A., Cuenca, A. M. B, Noronha, D. P., \& Schor, N. (2007). Saúde reprodutiva: uma contribuição para avaliação de biblioteca virtual. Cadernos de Saúde Pública, 23(10), 23172326.

Bordini, G. B. (2010). As narrativas de adolescentes sobre gênero em um ambiente virtual. Dissertação de Mestrado Não-Publicada, Programa de Pós-Graduação em Psicologia, Universidade Federal do Rio Grande do Sul, Rio Grande do Sul.

Bruner, J. S. (2000). A cultura da educação (M. A. Domingues, Trad.). Porto Alegre: Artes Médicas. (Original publicado em 1996).

Cameron, K. A., Salazar, L. F., Bernhardt, J. M., Burgess-Whitman, N., Wingood, G. M., \& DiClemente, R. J. (2005) Adolescents' experience with sex on the web: results from online focus groups. Journal of Adolescence, 28(4), 535-540.

Chase, L., \& Alvarez, J. (2000). Internet Research: The Role of the Focus Group. Library \& Information Science Research, 22(4), 357-369.

De Antoni, C., Martins, C., Ferronato, M., Simões, A., Maurente, V., Costa, F., et al. (2001). Grupo focal: Método qualitativo de pesquisa com adolescentes em situação de risco. Arquivos Brasileiros de Psicologia, 53(2), 38-53.

Diamond, M. (2002). Sex and gender are different: sexual identity and gender identity are different. Clinical Child Psychology and Psychiatry, 7(3), 320-334.

Dias, A. C. G., \& La Taille, Y. de. (2006) O uso das salas de batepapo na internet: um estudo exploratório acerca das motivações, hábitos e atitudes dos adolescentes. Interação em Psicologia, 10(1), 43-51.

Duarte, A. B. S. (2007). Grupo Focal online e offline como técnica de coleta de dados. Informação \& Sociedade: estudos, 17(1), 81-95.

Fox, F. E., Morris, M., \& Rumsey, N. (2007). Doing synchronous online focus groups with young people: methodological reflections. Qualitative Health Research, 17(4), 539-547.

Georgakopoulous, A. (2007). Thinking big with small stories in narrative and identity analysis. In M. Bamberg (Org.), Narrative State of the Art (pp. 145-154). Amsterdam, Philadelphia: John Georgakopoulou, A. (2007). Benjamins Publishing.

Georgakopoulous, A. (2008). 'On MSN with buff boys': Self - and other - identity claims in the context of small stories. Journal of Socialinguistics, 12(5), 597-626.
Gondim, S. M. G. (2002). Grupos Focais como Técnica de Investigação Qualitativa: Desafios Metodológicos. Paideia (Ribeirão Preto), 12(24), 149-162.

Huffaker, D. A., \& Calvert, S. L. (2005). Gender, identity, and language use in teenage blogs. Journal of Computer-Mediated Communication, 10 (2), Recuperado em 6 de setembro, de 2010, de http://jcmc.indiana.edu/vol10/issue2/huffaker.html .

IBGE (2008). Acesso à internet e posse de telefone móvel celular para uso pessoal. Recuperado em 6 de setembro de 2010, de http://www.ibge.gov.br/home/estatistica/populacao/acessoainterne t/.

Kelly, G., \& McKenzie, B. (2002). Security, privacy, and confidentiality issues on the Internet. Journal of Medical Internet Research, 4(2), e12.

Kralik D., Price, K., Warren, J., \& Koch, T. (2006). Issues in Data Generation using Email Group Conversations for Nursing Research. Journal of Advanced Nursing, 53(2), 213-220.

Krueger, R. A., \& Casey, M. A. (2000). Focus Group: a practical guide for applied research (3rd ed.). Thousand Oaks: Sage Publications.

Louro, G. L. (2004). Gênero, sexualidade e educação: uma perspectiva pós-estruturalista (7a ed.). Petrópolis: Vozes.

Maxwell, J. A. (2005). Qualitative research design: An interactive approach (2a ed.). Thousand Oaks, CA: Sage Publications.

Nicolaci-da-Costa, A. M., Romão-Dias, D., \& Di Luccio, F. (2009). Uso de Entrevistas On-Line no Método de Explicitação do Discurso Subjacente (MEDS). Psicologia: Reflexão e Crítica, 22(1), 36-43.

O’Connor, H., \& Madge, C. (2003). Focus group in cyberspace: using the internet for qualitative research. Qualitative Market Research, 6, 133-143.

Schneider, S. J., Kerwin, J., Frechtling, J., \& Vivari, B. A. (2002). Characteristics of the Discussion in Online and Face-to-Face Focus Groups. Social Science Computer Review, 20(1), 31-42.

Subrahmanyam, K., Smahel, D., \& Greenfield, P. (2006). Connecting developmental constructions to the internet: Identity presentation and sexual exploration in online teen chat rooms. Developmental Psychology, 42 (3) 395-406.

Walston, J. T., \& Lissitz, R. W. (2000). Computer-Mediated Focus Groups. Evaluation Review, 24(5), 457-483.

Whitehead, L. C. (2007). Methodological and ethical issues in internet-mediated research in the field of health: An integrated review of the literature. Social Science \& Medicine, 65, 782-791.

Recebido em 16/09/2010 Aceito em 12/09/2011
Endereço para correspondência:
Gabriela Sagebin Bordini. Rua Aliança, 169, Bairro Jardim Lindóia, CEP 91050-010, Porto Alegre-RS, Brasil.E-mail: charlestonbordini@yahoo.com.br. 